\title{
NUEVAS FORMAS DE EXPRESIÓN EN LA LÍRICA RECIENTE: EL LENGUAJE LITERARIO Y LA RUPTURA DEL HORIZONTE DE EXPECTATIVAS
}

New ways of expression in the recent lyric genre: the literary language and the breakup of the horizon of expectations

\author{
JoSÉ ÁNGEL BAÑOS SALDAÑA
}

UNIVERSIDAD DE MURCIA (ESPAÑA) joseangel.banos@um.es

\section{RECIBIDO: 29 DE DICIEMBRE DE $2017 \quad$ ACEPTADO: 8 DE MARZO DE 2018}

RESUMEN: Debido a la idea extendida de que la poesía posmoderna se caracteriza por la preocupación lingüística y por la deconstrucción del proceso creativo, este artículo estudia cómo los poetas españoles nacidos en torno a 1980 trabajan con el lenguaje y con las convenciones del género lírico. En concreto, se centra en la desautomatización de unidades fraseológicas, en las correcciones expresas y en las referencias irónicas al proceso de escritura. Estos tres mecanismos, que albergan una visión desacralizada de la lírica, producen una ruptura de expectativas. La desautomatización de unidades fraseológicas adquiere un interés metalingüístico y metapoético porque se erige en un modo de renovación de la expresión poética en los autores nacidos en torno a 1980. Asimismo, las correcciones expresas y las referencias irónicas al proceso de escritura reclaman que la lírica no ha de poseer un esquema discursivo previo ni unas condiciones de recepción preestablecidas.

PALABRAS CLAVE: poesía contemporánea, unidades fraseológicas, desautomatización, correcciones expresas, ironía.

ABSTRACT: Due to the worldwide known idea which states that postmodern poetry is characterized by linguistic consciousness and by the deconstruction of the creative process, this paper studies how the Spanish poets born around 1980 work with the language and with the lyric genre conventions. Specially, this paper focuses on the de-automatization of phraseological units, on the explicit corrections and on the ironical references to the writing process. These three mechanisms, which present a demystified vision of the lyric genre, produce a breakup of expectations. The de-automatization of phraseological units acquires metalinguistic and metapoetic interest because it is a renovation of the poetic expression in the writers born around 1980. Besides, the express corrections and the ironic references to the writing process highlight that the lyric genre doesn't have a previous discursive pattern or pre-established conditions of reception.

KEYWORDS: contemporary poetry, phraseological units, de-automatization, express corrections, irony

Baños Saldaña, José Ángel.

"Nuevas formas de expresión en la lírica reciente: el lenguaje literario y la ruptura del horizonte de expectativas".

Kamchatka. Revista de análisis cultural 11 (Julio 2018): 111-126

DOI: 10.7203/KAM.11.11319 ISSN: 2340-1869

Monográfico Lecturas del desierto: nuevas propuestas poéticas en España 

1980

Viene siendo un lugar común en los estudios sobre poesía española reciente comenzar con una sagaz observación en la que se advierten las dificultades que entraña establecer categorías firmes. No será este caso una excepción. La lírica de los últimos tiempos se caracteriza fundamentalmente por su heterogeneidad (Andújar Almansa, 2007; Bagué Quílez, 2014a; Iravedra, 2014). Bagué Quílez y Santamaría (2013) han escrito al respecto que no existe una sola línea de progreso, sino que hay que atender a diversas bifurcaciones. Este artículo se propone analizar el uso del lenguaje literario por parte de los poetas nacidos en torno a 1980. En consecuencia, no se pretende describir un estilo unitario generacional, sino poner de relieve el interés que se deriva del estudio de rasgos formales en la lírica contemporánea.

A pesar de lo controvertido y, a veces, difuso que es el concepto de posmodernidad en España, se puede advertir una actitud diferente entre los autores modernos y los posmodernos. Ahora bien, no existe una frontera exacta entre ambos grupos, sino que los segundos emplean técnicas de los primeros desde otro prisma. Por ejemplo, es una tendencia emergente la naturalidad con la que se produce la coexistencia de alta y baja cultura, puesto que, como se verá en los textos analizados, ya no se recurre a ella con una intención provocativa. Rodríguez-Gaona (2010: 9-112) anota una serie de características sobre la posmodernidad que podríamos resumir sinópticamente en el siguiente esquema ${ }^{1}$ :

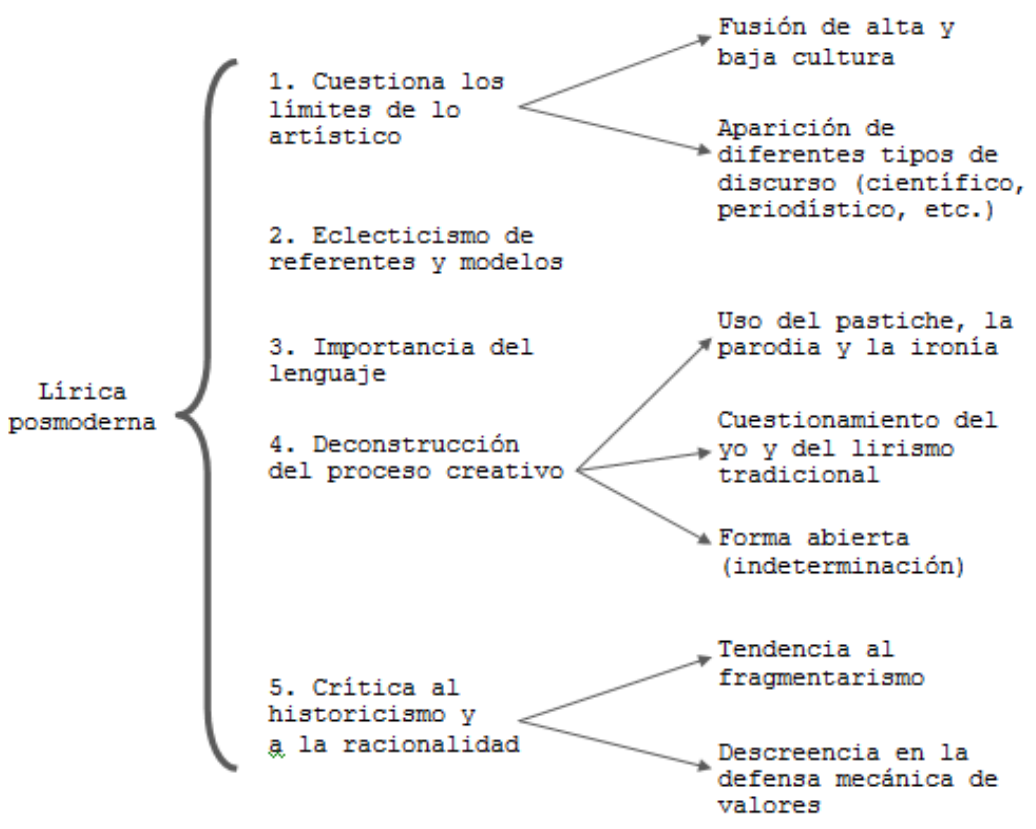

Esquema 1. La lírica posmoderna (elaboración propia)

\footnotetext{
1 En este artículo se abordarán una serie de técnicas textuales que pueden considerarse posmodernas. Lo posmoderno en España no siempre adquiere los mismos matices que en la literatura anglonorteamericana. De hecho, no todos los autores españoles contemporáneos emplean recursos posmodernos con la misma frecuencia.
} 
En relación con la importancia del lenguaje y la deconstrucción del proceso creativo, se abordará en estas páginas la desautomatización de $\mathrm{UF}^{2}$, las correcciones expresas y las referencias irónicas al proceso de escritura. Estos tres aspectos se relacionan estrechamente con la búsqueda de la ruptura de expectativas y con una visión desacralizada de la lírica. Así pues, aunque no todos los poemas analizados son metapoéticos, sí contienen una concepción poética implícita. El poeta no se muestra como una autoridad literaria; por ello, exhibe las condiciones de artificio de la poesía, al mismo tiempo que, implícitamente, transmite unas convicciones estilísticas. El valor implícito del discurso poético incentiva la actividad del lector, cuya finalidad primera consiste en captar aquello que va más allá de lo literal3.

El empleo desautomatizado de UF fue uno de los recursos más importantes de los poetas sociales (Le Bigot, 1993). Por ejemplo, en "A la inmensa mayoría” (Pido la pazy la palabra, 1955) Blas de Otero (2016: 227) escribió: "Aquí tenéis, en canto y alma, al hombre// [...] Aquí tenéis, en carne y bueso, mi última voluntad" [la cursiva es mía]. Gabriel Celaya (2001: 717), por su parte, alteró un patrón religioso en "La poesía es un arma cargada de futuro" (Cantos iberos, 1955): "nuestros cantares no pueden ser sin pecado un adorno" [la cursiva es mía]. Del mismo modo, Jaime Gil de Biedma (2010: 153) compuso el poema "En el nombre de hoy" (Moralidades, 1966) [la cursiva es mía].

La diferencia entre los autores del 40 o del 50 y los nacidos en torno a 1980 estriba en que estos últimos no recurren a las UF para erigirse en portavoces sociales o para conseguir un tono confesional. Al contrario, la nueva poesía desautomatiza el lenguaje con la intención de convertir el poema en un "arma cargada de sentidos” (Bagué Quílez y Santamaría, 2013: 14). No obstante, poetas anteriores como Ángel González", Aníbal Núñez o Víctor Botas sentaron un precedente. Así, el primero en "Playa nudista (Venice, California)" (Prosemas o menos, 1985) calificó a los bañistas como “[...] almas/ en pene" (González, 2015: 365) [la cursiva es mía]. Aníbal Núñez, por su parte, en "Final" (Naturaleza no recuperable, [1976] 1991) reforzó su defensa ecológica refiriéndose al sol en los siguientes términos: "pon de luto la luz ya para siempre:/ apaga y vámonos..." (Núñez, 1995: 117) [la cursiva es mía]. Pero es Víctor Botas quien se acerca más al estilo de los poetas que se

\footnotetext{
${ }^{2}$ Unidad(es) fraseológica(s).

${ }^{3}$ A tal efecto, Rodríguez-Gaona (2010: 33) escribe: “[...] el lector ideal de estos autores no es alguien que les deba un reconocimiento previo o una autoridad social heredada gracias a un consenso institucional. [...] [L]a exhibición crítica o irónica de la cocina poética no solo hace tangible un oficio antes lejano por secreto, sino que constituye una vía de conocimiento hacia la subjetividad escindida y problemática del autor y sus relaciones con el mundo".

4 Aunque Ángel González se enmarca en la generación del 50, su poesía es uno de los casos en que las UF se desautomatizan con un propósito parecido al de los poetas recientes. Sin embargo, también posee poemas que ponen la desautomatización a disposición de la denuncia social. Véase «Camposanto en Colliure» (Grado elemental, 1962): "Aqui paz/ y después gloria.// Aqui/ a orillas de Francia,/ en donde Cataluña no muere todavía/ y prolonga en carteles de "Toros à Ceret" / y de "Flamenco's Show"/ esa curiosa España de las ganaderías/ de reses bravas y de juergas sórdidas,/ reposa un español bajo una losa:/ paz/ y después gloria.// Dramático destino,/ triste suerte/ morir aquí/ - paz/ y después.../ perdido [...]// Sí; después gloria// Al final del verano,/ por las proximidades/ pasan trenes nocturnos, subrepticios,/ rebosantes de humana mercancía:/ mano de obra barata, ejército/ vencido por el hambre/ - paz...-,/ otra desbandada de españoles/ cruzando la frontera, derrotados / - ...sin gloria.// Se paga con la muerte/ o con la vida, [...]// ¿Qué precio es el peor?/ Me lo pregunto/ y no sé qué pensar/ ante esta tumba,/ ante esta paz/ [...] ante la gloria esta/ [...] que yace aquí [...].// Quisiera,/ a veces,/ que borrase el tiempo/ los nombres y los hechos de esta historia/ como borrará un día mis palabras/ que la repiten siempre tercas, roncas.” (González, 2015: 157-158) [la cursiva es mía].
} 
analizarán. En "Página en blanco" (Historia antigua, 1987) no solo se desautomatiza una UF, sino que también -como se verá más adelante- se incluye una referencia irónica al proceso de escritura:

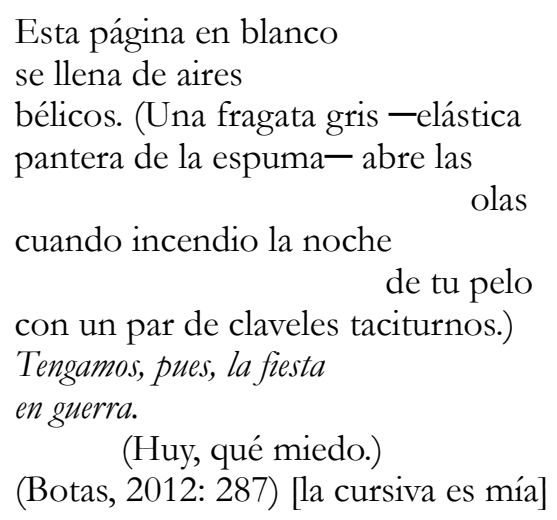

En la lírica reciente la subversión lingüística (Iravedra, 2016) se debe al interés por evitar lo pre-decible (Martínez, 2013) y a una actitud irónica frente a los prejuicios genéricos. Debido a que "la expresión poética sigue aferrada al estereotipo de una ingenuidad más aparente que real” (Bagué Quílez y Rodríguez Rosique, 2013: 296), los autores se rebelan mediante la explotación de los recursos lingüísticos (ironía, parodia, desautomatización) y mediante la ruptura del discurso tradicional. En este sentido, "las indagaciones personales alternan con las introspecciones lingüísticas” (Andújar Almansa, 2007: 31).

Esta mirada hacia las condiciones del género y hacia el instrumento que permite su creación (el lenguaje) desencadena una serie de procesos textuales que, si bien existían con anterioridad, se emplean ahora de manera profusa. Las correcciones expresas y las referencias punzantes al proceso de escritura constituyen ejemplos de ironía en segundo grado5. En ellos el efecto irónico actúa sobre el horizonte de expectativas que produce el género (Bagué Quílez y Rodríguez Rosique, 2013). Así, en el poema ya citado de Botas, el verso "(Huy, qué miedo.)" provoca una ruptura de expectativas con la que el autor se burla de la afectación y del patetismo poéticos.

Así las cosas, ante una poesía nihilista e irónica (Morales Barba, 2009) que cuestiona sus propios fundamentos (Prieto de Paula, 2014), es conveniente un acercamiento teórico que tenga en cuenta las modificaciones del uso común del lenguaje y de las convenciones genéricas. En cuanto a la desautomatización de UF, conviene prestar atención al efecto pragmático (Olza y Manero Richard, 2013) que desencadenan los rasgos formales y contextuales. Las correcciones expresas y las referencias al proceso de escritura se estudiarán desde el punto de vista de la ironía metaformal (Bagué Quílez y Rodríguez Rosique, 2013).

\footnotetext{
${ }^{5}$ Este concepto lo acuñan Bagué Quílez y Rodríguez Rosique (2013: 298): “la ironía de segundo grado se erige en un tipo específico de intertextualidad, que consiste en la inversión del modelo discursivo que se toma como punto de partida".
} 


\section{LA DESAUTOMATIZACIÓN DE UF}

Los rasgos que definen las $\mathrm{UF}^{6}$ son, principalmente, la fijación y la idiomaticidad (Mena Martínez, 2002). En este artículo las UF que se analizarán también se caracterizan por la polilexicalidad. Corpas Pastor (1996: 20) define UF de la siguiente manera:

[L]as unidades fraseológicas [...] son unidades léxicas formadas por más de dos palabras gráficas en su límite inferior, cuyo límite superior se sitúa en el nivel de la oración compuesta. Dichas unidades se caracterizan por su alta frecuencia de uso, y de coaparición de sus integrantes; por su institucionalización, entendida en términos de fijación y especialización semántica; por su idiomaticidad y variación potenciales; así como por el grado en el cual se dan todos estos aspectos en los distintos tipos.

La fijación se debe a que las UF son expresiones que se repiten en la diacronía de la lengua (Zuluaga Ospina, 1980). En este sentido, la desautomatización en la lírica contemporánea responde al interés por renovar la expresión poética. La variabilidad no rechaza la fijación, sino que la refuerza porque se produce gracias a ella (Corpas Pastor, 1996; Zuluaga Ospina, 2001; Mena Martínez, 2002).

Para generar una UF desautomatizada, deben concurrir tres factores (Mena Martínez, 2002): 1) intencionalidad en la modificación; 2) un desvío en la modificación con respecto a la forma original para que se perciba el cambio; 3) una forma base reconocible a través de los elementos conservados o del contexto. El marco comunicativo de los poemas que se analizarán a continuación es el siguiente:

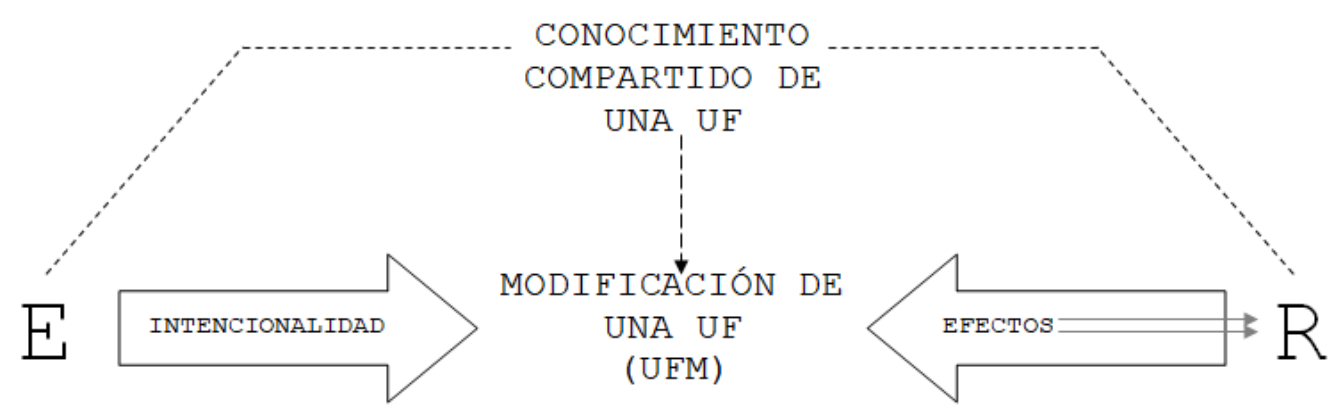

Esquema 2. La modificación de UF (elaboración propia a partir de Mena Martínez [2002])

Para que los efectos intencionales que produce el emisor (E) por medio de la UFM (unidad fraseológica modificada) tengan éxito, el receptor (R) ha de conocer la forma base sobre la que se lleva a cabo la modificación. De esta manera, el poeta realiza un ejercicio de "producción en la reproducción" (Mena Martínez, 2002: 169) que, habida cuenta del principio de relevancia (Sperber y Wilson, 1994; Corpas Pastor, 1996; Ruiz Gurillo, 1998; Mena Martínez, 2002), el lector decodifica. En otros términos, el receptor lleva a cabo un esfuerzo que se satisface con los múltiples efectos de sentido que provoca la desautomatización. Entre ellos, Zuluaga Ospina

\footnotetext{
${ }^{6}$ La clasificación de las UF que se emplea en estas páginas proviene de la teoría de las tres esferas de Corpas Pastor (1996), a saber: colocaciones, locuciones y enunciados fraseológicos.
} 
(1980) y Vigara Tauste (1986) destacan la reflexión metalingüística, lo cual entronca con uno de los aspectos fundamentales de la poesía contemporánea.

El tema metaliterario - tanto en forma de poética explícita como implícita- sobresale por su profusión a lo largo del siglo XX hasta hoy (Martín Estudillo, 2003; Pérez Parejo, 2007). Sin embargo, la constante reflexión metalingüística y metapoética a través de la desautomatización de UF se desarrolla particularmente con los poetas nacidos en torno a 1980.

Andrés Neuman, por ejemplo, es uno de los autores contemporáneos en los que lo metaliterario adquiere un papel principal. De hecho, en Década (2012), recopilación de su poesía hasta 2007, introduce al inicio una nota del autor, titulada "El prójimo latente" (Neuman, 2012: 15-19), en la que reflexiona sobre el oficio de poeta y en la que apunta que la prioridad de un poema es la creación de significados.

En lo relativo a la concepción del lenguaje literario, Neuman adopta una actitud desacralizadora. Así, en "Monólogo a dos voces" (Métodos de la noche, 1998) despliega un estilo excesivamente retórico en las estrofas impares, mientras que en las pares lo contrarresta mediante diferentes estrategias de ruptura? . La reivindicación del uso del lenguaje cotidiano ("bastante nos costó vestirlo de paisano”) y desacralizado (“iHay que soltar los cirios [...]!”) no implica una despreocupación. Al contrario, en la poesía de Neuman cada palabra cuenta. Sobre este aspecto versa "Gota de luz" (Mística abajo, 2008):

[...] Porque he sido feliz este minuto y debo recordarlo en adelante.

Porque he sido feliz, y algo muy sordo hemos debido hacer con las palabras cuando pueden sonarnos triviales al decir maravillas.

(Neuman, 2007: 172)

La reflexión metapoética, que en este caso está explícita, se construye sobre la desautomatización de la UF. A través de un proceso de modificación formal con cambio semántico, el autor emplea una sustitución paronímica por la que la colocación hacer algo muy gordo deviene en hacer algo muy sordo. Esta estructura conserva el significado y los implícitos generados por la forma base, al mismo tiempo que actúa como causa de la conclusión del poema gracias a la continuación semántica: hacer algo muy sordo $>$ las palabras pueden sonarnos triviales.

El mismo recurso utiliza Martha Asunción Alonso para desautomatizar la UF gajes del oficio en el poema en prosa “Gajos del oficio" (Wendy, 2015). Este consta de seis partes breves (o gajos) en las que se muestra una serie de acontecimientos que le suceden cuando la invitan como poeta a diferentes eventos. La primera describe la asistencia de un alcalde del Partido Popular y de un antiguo amor a su recital. La segunda es un agradecimiento a un desconocido que, tras una mesa redonda, se acercó y le dijo: Estás muy verde. En la tercera cuenta que una señora que había asistido a un recital para jubilados en Pamplona la trató como "a una nieta que vuelve de Erasmus" (Alonso, 2015: 72), pero, en cuanto empezó a recitar, "se puso [...] a roncar como un tractor averiado". Cuando finalizó el acto, la vecina le dijo "Vámonos, Maricarmen, que aquí está

\footnotetext{
7 Estrofa 2: "Pero, idiota, qué asombro va a quedarnos [...]".// Estrofa 4: "Tranquilo, por favor, no desvariemos
} [...]”.// Estrofa 6: “jHay que soltar los cirios [...]!”.// Estrofa 8: “En fin...” (Neuman, 2012: 27-28). 
to'l pescao vendío". La autora, de nuevo, desautomatiza la UF concluyendo: "Y era verdad. No me quedaba ni una trucha" [el subrayado es mío]. Con la siguiente parte manifiesta su sorpresa cuando, por participar "en saraos culturetas varios" -nótese el tono irónico-, recibe cheques del Ayuntamiento, en cuyo concepto se lee "monitor deportivo" u "otros". En la quinta parte confiesa que, cuando fue a un instituto a explicar la utilidad de la literatura a alumnos conflictivos, las preguntas finales fueron "si tenía Tuenti, si quería cacho, si fumaba porros y si era bollera" (Alonso, 2015: 73). Por último, recuerda que en un "café-librería" un niño de tres años lloraba cuando leía sus versos y dejaba de llorar cuando paraba para tomar aire o para dar un trago a la cerveza. Termina el poema afirmando: "[a]quel crío de tres años es el único ser sobre la Tierra que de veras me entiende".

Por medio de la desautomatización en el título y de la simple exposición de lo acaecido, se desacraliza la figura del escritor. Al igual que en Neuman, la UFM mantiene el significado y los implícitos de la forma base; no obstante, se añaden sentidos que van más allá de la mera finalidad humorística, como, por ejemplo, la mitigación de las molestias que tales hechos le provocan.

Ahora bien, uno de los poetas contemporáneos que más recurre a la desautomatización de UF es Luis Bagué Quílez ${ }^{8}$. Este recurso destaca en los libros Paseo de la identidad (2014) y Clima mediterráneo (2017). El primero se abre con una "Oración en Starbucks", dividida en tres partes: "Introito", "Plegaria Latte (Acción de gracias)" e "Himno Mocca (Nocturno)". Desde el título, se rompe con las expectativas de la oración religiosa mediante el empleo de un sintagma locativo ("en Starbucks") poco adecuado al rezo. Asimismo, la primera parte, denominada "Introito", juega con la doble acepción del término, debido a que puede entenderse como el inicio de una oración, pero, además, como una especie de resumen de la obra. El poema dice:

Starbucks es el mundo.

El eterno dilema - mocca o latte-

se cuece en un crisol de credos maniqueos.

Café o té. Sacarina o azúcar,

nube blanca o morena. Navegamos

en red wifi o conexión por cable.

Conservar el recibo o destruirlo,

trizar su dignidad en papeleras verdes, camufladas detrás del rododendro.

Distribuidas en Este y en Oeste,

las latitudes son intercambiables, pero en todas

una sed estratégica nos quema la garganta.

Tantas cosas con haz y con envés

nos lanzan a la cara el guante de la duda:

¿qué demonios

hemos venido a hacer aquí?

(Bagué Quílez, 2014b: 9)

\footnotetext{
${ }^{8}$ Léase uno de los fragmentos de "Palo alto" (Paseo de la identidad) para ver cómo exprime los recursos lingüísticos combinando UF normales y UF desautomatizadas: "Pon manos a la obra,/ las barbas a remojo,/ los pies en polvorosa./ No te vuelvas/ corazón en un puño,/ no te rindas de tripas con razón./ Escribe/ con la mano en el pecho y los pies en la tierra./ Es decir,/ anda con ojo, mira/ la superficie de este mundo.// Que a tu cuerpo le llegue la camisa/ Que la sangre te llegue a la cabeza” (Bagué Quílez, 2014b: 29-30).
} 
La frase en la que se encuentra la UFM se formula como una síntesis del contenido. El verso 12 ("Tantas cosas con haz y con envés") actúa no solo como elemento que recoge la diseminación de disyuntivas, sino también como resumen de otras dualidades opuestas que implican la toma de decisiones. De esta manera, la desautomatización de la UF viene a expresar el agobio que produce tener que decantarse por opciones insustanciales, que, por otra parte, son las que ofrecen el capitalismo y la globalización.

El verso 13 ("nos lanzan a la cara el guante de la duda") merece una especial atención, puesto que se da la modificación formal por fusión' de dos UF ('arrojar el guante’ y 'el germen de la duda'). La primera sufre una modificación por sustitución léxica a través de términos sinonímicos ('lanzar' por 'arrojar') y por extensión (nos lanzan 'a la cara' el guante). Esto último constituye un ejemplo de cómo Bagué Quílez explota las propiedades de las UF para generar significados implícitos. Pero el interés de este verso reside fundamentalmente en la desautomatización que se produce cuando se realiza el proceso de fusión. Así, la sustitución léxica ('guante' en lugar de 'germen') reclama la sensación de extrañeza del lector que, justo después de este verso, llega a una interrogación -reforzada por una UF respetada ('qué demonios')- ambigua que conecta con el primero (“Starbucks es el mundo"). Esto es, la pregunta ya no es solo qué hemos venido a hacer en Starbucks, sino también en el mundo.

Seguidamente, tras la simulación de una Acción de gracias profana en "Plegaria Latte", escribe un himno báquico ("Himno Mocca”) (Bagué Quílez, 2014b: 11). En este poema desautomatiza consecutivamente tres enunciados fraseológicos. Los dos primeros se basan en el lema heraclitiano Nadie se baña dos veces en el mismo río. Así, la primera desautomatización es una modificación formal por sustitución léxica vinculada al contexto ("Nadie bebe dos veces/ la misma mezcla de Starbucks"), mientras que la segunda añade la sustitución paronímica ("No es posible salir/ igual del mismo rito"). La tercera, en cambio, consiste en una modificación formal por sustitución de miembros, de manera que una parte de la cita religiosa "El verbo se hizo carne y habitó entre nosotros" (Juan 1: 14) se reemplaza por "La excepción se hizo mocca/ y habitó entre nosotros".

Aunque la mayoría de desautomatizaciones de UF que se dan en el discurso lírico son formales, en Bagué Quílez se hallan varios casos de modificaciones semántico-contextuales ${ }^{10}$. En "Biología marina" (Paseo de la identidad) se despliega un díptico de contrarios, mediante el cual se realiza una crítica ecológica11. En este caso, se oponen la despreocupación humana por la

\footnotetext{
${ }^{9}$ Christine Palm (1995 apud. Mena Martínez, 2002: 121) define este procedimiento como “mezclas de dos o más UF que, cuando no constituyen producciones erróneas involuntarias, pueden ser introducidas conscientemente como mecanismo estilístico para conseguir determinados efectos concentrados".

10 En "La familia de Juan Carlos I" (Clima mediterráneo) se describe a la familia real siendo retratada por Antonio López ("Antonio López mira, corrige, se retrasa./ Lo apremian con los plazos. A veces está a punto/ de abdicar" [Bagué Quílez, 2017: 25]). No obstante, en un determinado momento se les atribuyen a los retratados las siguientes palabras: "Di patata. Di Luis. [...]". La segunda UF se desautomatiza semántico-contextualmente porque pierde el valor no referencial del nombre propio para poner su foco de atención en el nombre del poeta. Se produce un efecto semántico de ambigüización o, más concretamente, de remotivación, pues predomina el significado fraseológico, pero se activa, a la vez, el de la base derivacional (Mena Martínez, 2002). De este modo, lo que en principio era una expresión que se emplea para hacer una fotografía deja ver una marca autorial. En otras palabras, el poema lleva a cabo un doble retrato: el que realiza Antonio López y el que traza Luis Bagué Quílez.

11 A tal efecto, en el paratexto inicial se lee: "Con Jorge Riechmann”.
} 
contaminación a través de las condiciones de libertad precaria de los "Lobos marinos (Mar de Plata)" a la apariencia de concienciación ecológica a través de la visita a un recinto de "Leones marinos (San Francisco, Pier 39)". Sobre estos últimos, escribe no sin cierta ironía: "Se dejan ver el tiempo que dura el parpadeo/ del flash: sus derechos de imagen/ no contemplan la opción de pasar por el aro" (Bagué Quílez, 2014b: 17) [la cursiva es mía]. En estos versos se violan las condiciones semánticas de selección, ya que la UF necesita un sujeto humano. Así, se genera un efecto semántico de polisemantización, es decir, se mantienen los dos planos de significación (literal e idiomático), para tratar con un humor crítico la peculiar situación de unos animales que se dejan querer a cambio del "[...] alquiler de una casa flotante,/ una dieta rica en omega 3,/ la gabela del turismo ecológico".

En definitiva, el estudio del uso del lenguaje literario en la poesía española contemporánea permite profundizar en aspectos formales que alumbran el análisis del contenido y la interpretación pragmática del poema. La capacidad de las UF para cargar el discurso de sentidos con pocas palabras motiva el empleo de la desautomatización. Dicho de otra manera, la concisión, rasgo inherente al género lírico, encuentra su mejor aliado en las UF.

\section{UNA NUEVA MIRADA HACIA EL GÉNERO: LAS INTERVENCIONES DEL AUTOR EN EL POEMA}

Los textos que se analizarán a continuación rompen el horizonte de expectativas derivado del género. La ironía metaformal "revierte en la manera de decir, nombrar o contemplar el mundo” (Bagué Quílez y Rodríguez Rosique, 2013: 298). A la inversión discursiva, en consecuencia, va ligada una concepción poética implícita. Los mecanismos de desvertebración del discurso lírico (Iravedra, 2016) que se estudiarán son las correcciones expresas y las referencias irónicas al proceso de escritura.

\section{A) Las correcciones expresas}

Este recurso afecta a la estabilidad del poema, dado que la composición simula construirse a medida que avanza la lectura. Es decir, se crea una falsa apariencia de interrupción del resultado de escritura por medio de referencias al proceso de creación. Se entiende que la interrupción es simulada porque se trata del texto publicado (no de un borrador).

Carlos Pardo escribió un poema sin título en Echado a perder (2007) que dice:

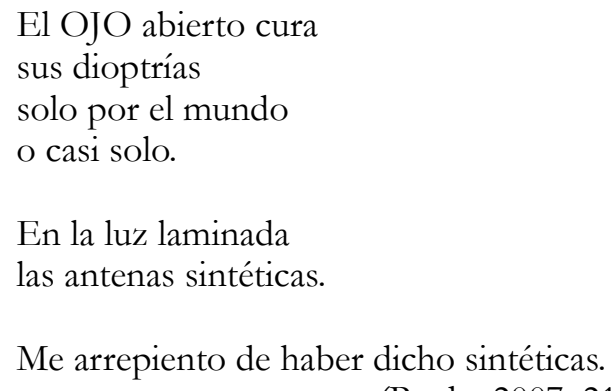

(Pardo, 2007: 21)

El último verso, al sancionar la elección de una palabra, plantea una reflexión metalingüística y metapoética (Bagué Quílez y Rodríguez Rosique, 2013) en concordancia con los 
procesos de desacralización. Esta visión de la escritura debe mucho a la poesía de Ángel González. De hecho, en "[El trabajo es precioso]” (Pardo, 2007: 53-55) desmitifica la figura del poeta versionando el "Para que yo me llame Ángel González]" (Áspero mundo, 1956) y el "Exegi monumentum" horaciano12: "Perdurará mi nombre, hasta/ donde sé, en las personas/ que vuelvan a llamarse Carlos Pardo,/ y quizá alguno, por curiosidad,/ hojee este libro" (Pardo, 2007: 54). Carlos Pardo ironiza sobre la pervivencia de su obra otorgándole un doble sentido a la perduración de su nombre. En contraste con una situación normal en la que los 'lectores' futuros mostrasen 'interés' por 'leer' su libro, escribe que perdurará solo en aquellos que se llamen 'Carlos Pardo', de los cuales alguno quizá -modalizador epistémico que refuerza la ironía- sienta 'curiosidad' por 'hojearlo'.

Partiendo de una motivación diferente, también Andrés Neuman y Alberto Santamaría realizan correcciones expresas. El primero rompe las expectativas del lector al cuestionar la capacidad de representación de la palabra poética:

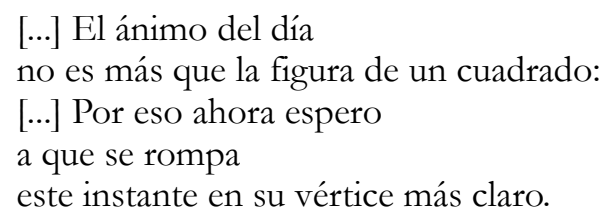

En este caso la corrección se presenta como una matización, pues el término 'ahora' no señala el instante inmediato.

Alberto Santamaría, en cambio, subvierte las convenciones genéricas en el poema en prosa "Menú" (Yo, chatarra, etc., 2015) gracias al uso de la corrección expresa en forma de negación textual que reformula lo escrito: "Llegó aquí con diecisiete años. No. Asi no. Érase una vez alguien que entró por esa puerta y se detuvo [...]” (Santamaría, 2016: 239) [la cursiva es mía]. El empleo de la corrección al principio puede relacionarse también con una reflexión metapoética sobre cómo iniciar el poema. El matiz irónico de la negación se basa en la reformulación de lo anterior por medio del cliché "érase una vez".

Otro poema en prosa en el que se recurre a la corrección expresa es "Ciencia exacta" (Wendy), de Martha Asunción Alonso:

[...] Ignoro cuántas naranjas caben en 14 cestas, por mucho que don Javier me repita que en cada cesta caben ocho docenas. Ah, ¿que eran huevos? Pues tampoco. Ni santa idea

(Alonso, 2015: 39)

En este texto se halla el uso del mecanismo que se está analizando, pero también se incorporan referencias irónicas al proceso de escritura. En cuanto a la corrección, cabe advertir

\footnotetext{
12 Véase la importancia de la pervivencia del nombre en Horacio: "Levanté un monumento más perenne que el bronce, / [...] que ni las inclemencias/ ni la incesante figura de los años/ lograrán destruir. No moriré/ del todo, [...]/ siempre renovando, crecerá/ mi fama en los que vengan $[\ldots] /[\ldots]$ Y correrá/ mi nombre del Aufido/ a los reinos del Dauno [...]" (Horacio apud. Botas 2012: 160-161).
} 
que esta vez se produce a causa de la mímesis de la oralidad espontánea; esto es, se habla del objeto ('naranjas') de una operación matemática que, repentinamente, se recuerda mejor y se sustituye, de ahí la interjección 'ah' y la interrogación posterior.

B) Referencias irónicas al proceso de escritura

La estabilidad del poema también se cuestiona con las referencias irónicas al proceso de escritura. La hipertrofia de la oralidad coloquial en "Ciencia exacta" manifiesta una actitud subversiva ante las características prototípicas del género. En este sentido, el uso de UF adquiere gran importancia. Aunque se puede comprobar en el fragmento anterior ('Ni santa idea'13), destaca el comentario que realiza entre paréntesis tras afirmar que no sabe resolver polinomios: "(¿qué narices, por cierto, es un polinomio? ¿Será muy contagioso? Condón, por si las moscas" (Alonso, 2015: 39) [la cursiva es mía]. El enfrentamiento contra la idea extendida de que el género lírico equivale a la arquitectura del lenguaje perdura hasta el final. Así, el poema se cierra no solo con la coloquialidad que mantiene desde el inicio, sino también con una llamada de atención sobre el valor semántico del broche final: "RESUMIENDO: soy hija de la LOGSE.// Y de letras, encima.// No conozco más ciencia exacta que mi amor” (Alonso, 2015: 41).

Otros mecanismos irónicos en relación con el proceso de escritura se fundamentan en el cambio de la lectura normal a una lectura metadiscursiva mediante la apelación al conocimiento compartido (Bagué Quílez y Rodríguez Rosique, 2013). Esto sucede en un poema sin título de Echado a perder de Carlos Pardo y en "A Virginia, madre de dos hijos, compañera de primaria de la autora"14 (Chatterton, 2014) de Elena Medel. En el primero se concluye con unos versos ("[...] y sigue/ una enumeración") en los que se sustituye el discurso poético por el procedimiento retórico, de manera que el poema se queda sin un final cerrado.

$\mathrm{Y}$ todo tiene un aire presexual.

El mar apesta a olas

hormonadas, y para despistar

los albañiles

cortaban en la calle baldosas.

Era la primavera, y sigue

una enumeración.

(Pardo, 2007: 31)

\footnotetext{
${ }^{13}$ Este es un caso paradigmático de UFM, ya que el adjetivo "santa" invierte el predecible ("puta": "Ni puta idea").

${ }^{14}$ A pesar de su extensión, el análisis del recurso estudiado necesita la lectura del poema: "Ocupáis tres asientos frente a mí en el autobús que se desplaza/ desde nuestro barrio alejado del centro/ al centro;/ al centro de nuestra localidad minúscula, entiéndase, no al centro de las cosas, no a la esencia misma ni a la materia nuclear donde la vida// bang// donde la vida// se expande y obedece a todos los fenómenos -etcétera- que dicta/ la astrofísica. Lo proclaman las asignaturas que rodeábamos porque éramos de letras [...]// Ocupáis tres asientos frente a mí/ en la parte trasera del transporte público: el niño a la derecha, en el centro la niña, la madre a la izquierda./ Ahora tú, hija pequeña de Virginia: chándal rosa gastado -igual/ que los plumieres de tu madre- con un personaje/ que mi edad y condición soltera ignoran.// Ahora tú, hijo mayor de Virginia, intuyo en tu barbilla y tus orejas/ los rasgos que heredaste de tu padre, y me pregunto/ si Virginia los maldice/ -Virginia, clos maldices?-/ a la hora del baño.// Pero tú, Virginia, tan rubia, ¿lo recuerdas?/ Allá donde entonces combatíamos piojos// ahora// bang// escondemos el tiempo.// [...] [O]h Virginia, oh rubia e inocente,/ yo he pensado en nosotras,// bang// yo he pensado en nosotras.// No sé si sabes a lo que me refiero.// Te estoy hablando del fracaso" (Medel, 2014: 45-47).
} 
En el de Medel, en cambio, la expresión etcétera elimina una enumeración que no conviene empezar con el fin de dar protagonismo al contenido: el fracaso. La impresión que le produce el fortuito encuentro con una compañera de primaria no solo se manifiesta en el contenido, sino también en la ruptura de la linealidad del poema. Véase la interrupción que la interjección bang ejerce sobre el discurso, pues las tres veces que se emplea se repite el verso que le precede como continuación:

1. [...] donde la vida// bang// donde la vida [...]

2. [...] ahora// bang// ahora [...]

3. [...] yo he pensado en nosotras, // bang// yo he pensado en nosotras [...]

Este mecanismo iterativo se puede relacionar también con algunas estructuras musicales del blues o del rock.

Desde la revisión de las convenciones estructurales de un libro de poesía, José Alcaraz compuso Edición anotada de la tristera (2013), obra en la que todos los poemas son notas a pie de página y en la que al final se incluye una "Bibliografía" que dice: "febrero, marzo, abril, junio, julio, agosto, septiembre, octubre y noviembre" e incorpora diferentes lugares de Cartagena, a saber: Café Ficciones, Ciudad Jardín, La Manga del Mar Menor, Las Lomas, Parque de la Rosa, Parque de Los Juncos, Plaza San Francisco y Puerto. Incluso en un poema se dirige exclusivamente al lector para ausentarse, debido a la intensidad con la que experimenta la poesía: "Permitidme/ un instante.// Gracias" (2013: 44). Estos versos desautomatizan el género y encierran una nueva concepción metapoética, dado que el receptor no espera que se le solicite un momento de relajación. Aún más, la ironía adquiere importancia debido al contexto poemático, pues en la composición anterior se entrevé que los poetas son, al mismo tiempo, una fuente de reflexión y unos aguafiestas: "Nada que no arruine/ mis ganas de salir.// Menudos los poetas;/ peores que la lluvia" (Alcaraz, 2013: 43).

La desacralización de la figura del escritor también se observa en "Pasión, eso"15 (Métodos de la noche) de Andrés Neuman y en "Escena sin moraleja" (Silbando un eco extraño, 2016) de Constantino Molina. Frente al estereotipo de la superioridad intelectual del poeta, Neuman se describe como una persona de carne y hueso:

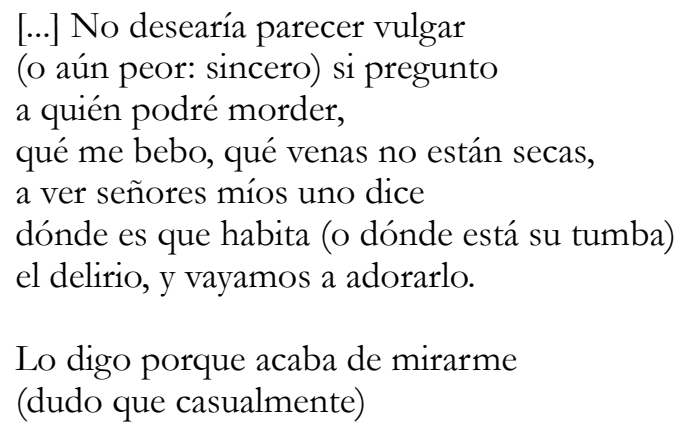

\footnotetext{
${ }^{15}$ En "Ropajes", poema que sigue al que se analizará, se invierten las propiedades de la lírica amorosa, pues, frente a la efusividad del poeta enamorado, se trata el tema de la impotencia verbal: "Decirte que te amo es una historia/ de mustias obviedades./ Sería preferible que leyeses/ amores novedosos [...]// Mi única destreza es protegerme.// Decirte que me ames es un pleito/ de lenguajes más hábiles que el mío [...]/ Decir te amo suele ser asunto/ de obvias melancolías" (Neuman, 2012: 43-44).
} 
alguien con ojos lúcidos y senos de banquete

(perdonen la asonancia, es que me turbo)

y entonces preguntaba más que nada

para saber si acaso aún existía

eso que en libros he leído tantas veces.

(Neuman, 2012: 41-42)

En un somero inventario de los mecanismos de desacralización de estas dos estrofas, cabe mencionar la cortesía irónica - "No desearía parecer vulgar"-; la alusión a la falta de veracidad del discurrir poético - "(o aún peor: sincero)"-; el uso de lo coloquial alternado con patrones corteses formales - "a ver señores míos uno dice"-; el recurso a la intertextualidad humorística - "dónde es que habita (o dónde está su tumba)"-; los comentarios hechos entre paréntesis - "(dudo que casualmente)"-; la asonancia intencionada - "[...] mirarme/ [...] casualmente)/ [...] senos de banquete"-; la retractación de la asonancia con una apelación formal a los lectores y con una justificación anómala - "perdonen la asonancia, es que me turbo"-; la reiteración de la pregunta que no se quería plantear - "y entonces preguntaba más que nada"-; y la insinuación de que los libros repiten el mismo tema con frecuencia - "para saber si acaso aún existía/ eso que en libros he leído tantas veces"-.

En la misma línea, Constantino Molina escribe "Escena sin moraleja":

Deslizo lentamente

la punta del cuchillo sobre el pan.

Me detengo en un punto

y voy hincando el filo

hasta llegar al fondo.

Hay que ser muy espléndido

para esperar que brote de esta herida

algo de sangre o una moraleja.

(Molina, 2016: 43)

La referencia irónica al proceso de escritura está explícita. Aunque ya desde el título se adelanta que no habría una moraleja, la estrofa final del poema se refiere únicamente a este respecto. Siguiendo las convenciones genéricas de las composiciones con moraleja, en la primera y en la segunda estrofa se presenta una acción cotidiana. La última, por el contrario, se distancia de dichas convenciones burlándose de la ingenuidad en la poesía ("Hay que ser muy espléndido").

Tanto las correcciones expresas como las alusiones irónicas al proceso textual constituyen una nueva visión sobre la lírica. A través de estos mecanismos, cabe destacar que una de las señas de los poetas nacidos en torno a 1980 es que la poesía no tiene un esquema discursivo previo ni unas condiciones de recepción preestablecidas.

\section{VUELTA AL PUNTO DE PARTIDA. ALGUNAS CONSIDERACIONES FINALES}

La continuidad de los recursos estudiados en los poetas nacidos en torno a 1980 no quiere decir que todos los compartan, pues la lírica reciente se caracteriza por su heterogeneidad. Ahora bien, en lo que sí coinciden -o en lo que se ven obligados a coincidir- es en la necesidad de 
tomar una postura ante la lírica. Esta actitud, cuando no se manifiesta en un metapoema, se ve reflejada en rasgos formales que evidencian una poética implícita.

Si el estudio de una época literaria requiere una sistematización de sus características principales, el siguiente paso es profundizar en cómo se manifiestan. Dado que los distintos trabajos sobre poesía española contemporánea justifican la existencia de una lírica posmoderna que presta atención al lenguaje y al envase textual (Bagué Quílez y Rodríguez Rosique, 2013), este artículo ha pretendido mostrar la relevancia que poseen los mecanismos de desautomatización de UF, las correcciones expresas y las referencias irónicas al proceso de escritura. De esta manera, el análisis de las modificaciones formales en los textos literarios explica su contenido.

Ante los nuevos tiempos, en los que la lírica queda relegada a un género menor, la desacralización de la escritura y de la figura del poeta no solo responde a una escasa confianza en el valor de lo literario en plena sociedad de consumo, sino también a una actitud burlesca frente a tal situación. Entonces, la ironía, la parodia y la ruptura de las expectativas del lector se prestan como la mejor armadura para el combate. 


\section{BIBLIOGRAFÍA}

Alcaraz, José (2015). Edición anotada de la tristeza. Valencia: Pre-Textos.

Alonso, Martha Asunción (2015). Wendy. Valencia: Pre-Textos.

Andújar Almansa, José. "Retrato robot de la poesía reciente". Paraíso: revista de poesía 2 (2007): 23-38.

BAGUÉ Quílez, Luis. "La poesía española bajo el efecto 2000 (Dos o tres cosas que sé de ella”. Ínsula: revista de letras y ciencias humanas 805-806 (2014a): 5-8.

Bagué Quílez, Luis (2014b). Paseo de la identidad. Madrid: Visor.

BAguÉ QuíLEZ, Luis (2017). Clima mediterráneo. Madrid: Visor.

BAgué Quílez, Luis y Rodríguez Rosique, Susana. "La ironía en segundo grado: (in)versiones discursivas en la poesía española reciente”. Bulletin of Hispanic Studies 90-3 (2013): 295-310.

Bagué Quílez, Luis y SANTAmaría, Alberto (2013). “2001-2012: Una odisea en el tiempo”. Bagué Quílez, Luis y SANTAmaríA, Alberto (eds.). Malos tiempos para épica. Madrid: Visor: 11-35.

BotAs, Víctor (2012). Poesía completa. Sevilla: La Isla de Siltolá.

CELAYA, Gabriel (2001). Poesías completas I. Madrid: Visor.

CORPAS PASTOR, Gloria (1996). Manual de fraseología española. Madrid: Gredos.

GIL De BIEdma, Jaime (2010). Poesía y prosa. Barcelona: Círculo de lectores/ Galaxia Gutenberg.

GonZÁLEZ, Ángel (2015). Palabra sobre palabra. Barcelona: Austral.

IRAVEDRA, Araceli. "Fundación de la poesía y función de la crítica". Ínsula: revista de letras y ciencias bumanas 805-806 (2014): 8-12.

IRAVEDRA, Araceli (2016). Hacia la democracia. La nueva poesía (1968-2000). Madrid: Visor.

LE Bigot, Claude. "La deconstrucción de la frase hecha en algunos poetas sociales (Blas de Otero, Ángel González, Jaime Gil de Biedma)”. Paremia 2 (1993):151-155.

MArtín Estudillo, Luis. "Hacia una teoría de la metapoesía". Revista de Estudios Hispánicos 2 (2003): págs. 141-152.

MARTíneZ, Erika (2013). "Valores portátiles: el sujeto bajo la crítica”. BAGUÉ QuíLEZ, Luis y SANTAMARÍA, Alberto (eds.). Malos tiempos para épica. Madrid: Visor: 49-65.

Medel, Elena (2014). Chatterton. Madrid: Visor.

MENA MARTÍNEZ, Florentina (2002). La desautomatización de las paremias inglesas por sustitución: un estudio cognitivo. Murcia: Universidad de Murcia.

Molina, Constantino (2016). Silbando un eco extraño. Madrid: Hiperión.

Morales BArbA, Rafael (2009). Poetas y poéticas para la España del siglo XXI. Madrid: Devenir.

Neuman, Andrés (2012). Década (Poesía 1997-2007). Barcelona: Acantilado. 
NúÑEZ, Aníbal (1995). Obra poética I. Madrid: Hiperión.

OlZA, Inés y MANERO RiCHARD, Elvira (2013). “Introducción: el necesario 'giro pragmático' en la Fraseología”. OlZA, Inés y MANero Richard, Elvira (eds.). Fraseopragmática. Berlín: Fran\&Timme: 7-23.

OtERO, Blas de (2016). Obra completa. Barcelona: Galaxia Gutenberg.

PARDO, Carlos (2007). Echado a perder. Madrid: Visor.

PÉREZ PAREJO, Ramón (2007). Metapoesía y ficción: claves de una renovación poética. Madrid: Visor.

PRIETO DE PAUlA, Ángel Luis. "Poesía y contemporaneidad: unas cuestiones de partida". Ínsula: revista de letras y ciencias humanas 805-806 (2014): 2-5.

Rodríguez-Gaona, Martín (2010). Mejorando lo presente. Poesía española última: posmodernidad, bumanismo y redes. Madrid: Caballo de Troya.

RuIZ GuriLlo, Leonor (1998). "La Relevancia de los procesos de desautomatización. Contribuciones relevantes en la conversación coloquial”. Actas del I Simposio Internacional sobre Análisis del Discurso. Madrid.

Santamaría, Alberto (2016). El huésped esperado. Madrid: La Bella Varsovia.

SPERBER, Dan y WiLSON, Deirdre (1994). La relevancia: comunicación y procesos cognitivos. Madrid: Visor.

Vigara Tauste, Ana María (1998). "Aspectos pragmático-discursivos del uso de expresiones fosilizadas en el español hablado". WOTJAK, Gerd (ed.). Estudios de fraseología y fraseología del español actual. Madrid, / Frankfurt: Iberoamericana / Vervuert: 97-127.

Zuluaga Ospina, Alberto (1980). Introducción al estudio de las expresiones fijas. Frankfurt: Peter Lang.

Zuluaga OSPINA, Alberto. "Análisis y traducción de unidades fraseológicas desautomatizadas". Phin $n^{\circ} 16$ (2001): 67-83. 